\title{
Commentary on "Radiation-induced leiomyosarcoma following mastectomy: a case report" by Wain et al.
}

\author{
Ian Jackson
}

Received: 1 April 2010 /Accepted: 1 April 2010 /Published online: 26 June 2010

(C) Springer-Verlag 2010

I have chosen to publish this paper as a reminder to be aware of postradiation ulceration. If this occurs, think malignancy. Biopsy should be done and, if positive, there should be wide resection and repair with well-vascularized tissue, muscle flap, and simple skin reconstruction — skin graft. Follow-up should be frequent, and any suspicious region should be biopsied.

This seems very elementary, but unfortunately these simple rules are not always obeyed. 